\title{
Classification and Factors Influencing Accounting Systems.
}

\section{Stylianou Tasos $1^{\text {st }}$ and Athianos Stergios $2^{\text {nd }}$}

1, 2 Department of Accoynting and Finance, Technological Education Institute of Central Macedonia, Terma Magnisias, 62124, Serres, Greece, +302321049175, as@ teiser.gr

\section{ABSTRACT}

This paper provides a brief review about the need for harmonization and the factors that are affecting the adoption of International Accounting Standards. These factors are the Legal System, the Taxation system, the Provider of Finance and culture. As an accounting system we the mean the accounting practices a company uses in order to prepare its annual financial reporting. Also we are analyzing in depth the Nobe's, (1998) model, which supports, that companies which have more outsider finance are from a weak-equity market and belong to a Class B accounting system (be interested more in creditors and taxes) and are more likely to change to a Class A accounting system (interested more in shareholders and investors, generally in those which have not got an internal relationship with the company).

Key words: Harmonization; Classification; International Accounting Standards.

JEL Classification: M40, M41, M49 Key Words: Accounting Harmonization, Accounting Policies

Corresponding Author: Athianos Stergios

\section{INTRODUCTION}

It is more than obvious that the global market is changing very fast over the last decades. Nowadays the businesses have much more motivations to enter the global business environment due to the amazing improvements we have in technology, capital removal, the need to create new revenue sources as well as the removal of the inter-country trade barriers. In order for investment growth to continue, there is a demand for financial statement comparability and more specific for a harmonization in the presentation of the financial statements. Alexander D. and Nobes C.W., (2004) mentioned that: "Harmonization is a process of increasing the comparability of accounting practices by setting bounds to their degree of variation".

The preparation and presentation of financial statements by different companies at both national and international level requires a common basis in order to ensure greater consistency, comparability and information capacity. In addition the opening of international financial markets, has given to the companies of the private sector the opportunity not only to switch to them and to search for new markets, but also to obtain loans. However that means that these companies should be consistent in their accounting records because other countries will be subject to other rules and standards for exporting an economic outcome. Therefore, the need for the standardization of the accounts at both national and international level is imperative. The way in which the financial figures and activities of the international economic and commercial organizations are measured and presented, affects both the potential users of the financial statements individually and the whole society.

The businesses that are affected by accounting differences across countries are companies that are internationally active and they need to use or prepare financial statements in accordance with the rules of other countries. An enterprise which intends to export its 
products will need to assess the creditworthiness and the overall business situation of the client company through its financial statements. Also, an enterprise wishing to borrow from a foreign bank should submit financial statements prepared in accordance with the accounting principles required or are familiar with the lending bank. But mainly standardization is applicable to the compilation of the financial statements of subsidiaries of multinational companies operating in different countries.

The subsidiaries are obliged to compile and publish accounting statements in accordance with the host country's rules and, on the other hand, accounting statements for incorporation into the parent company's accounts. The accounting statements must be in accordance with the accounting principles of the country in which it is established, but also and in accordance with the accounting practices of the corporate group which it belongs as a subsidiary. Accounting standardization is likely to entail significant additional costs for businesses as accounting procedures and compliance with applicable standards and as well as checking compliance with the standards.

According to how companies are financed in different countries, Nobe's, (1998) model provides two types of financial systems. The bank-dominated and the market-oriented. Based on La Portal et al., (1998) there are many differences on how companies are financed and they argue that the extent of legal protection of the investors that every country provides could explain these differences. Some other authors are claiming that the companies, which seek to obtain external sources of finance, are more likely to provide more information to outsiders who are interested in understanding the financial documents (Choi, 1973; Diamond and Verrecchia, 1991; Botosan, 1997). The idea dominating Nobe's, (1998) model is consistent with the studies reported above. It is addressed to those countries which base their finance on external sources and are more likely to use accounting systems that provide greater amount of information.

\section{MATERIALS AND METHODS LITERATURE REVIEW}

\section{Harmonization of IAS's: The Need, the Role and the Advantages}

The economical expansion to new markets propelled the design of a common international accounting system. The latter will help external users from other countries, with different accounting principles, cultures, laws, e.t.c., to relay on the financial statements prepared under the rules of a uniform accounting system. All the above factors are those which influence the formulation of accounting rules and practices prevailed in each country and therefore their accounting systems as a part of the general social-economical environment. Figure 1 depicts the variables, which can determine differences in Accounting Systems:

\section{Figure 1: "Factors affect the adoption of International Accounting Standards"}

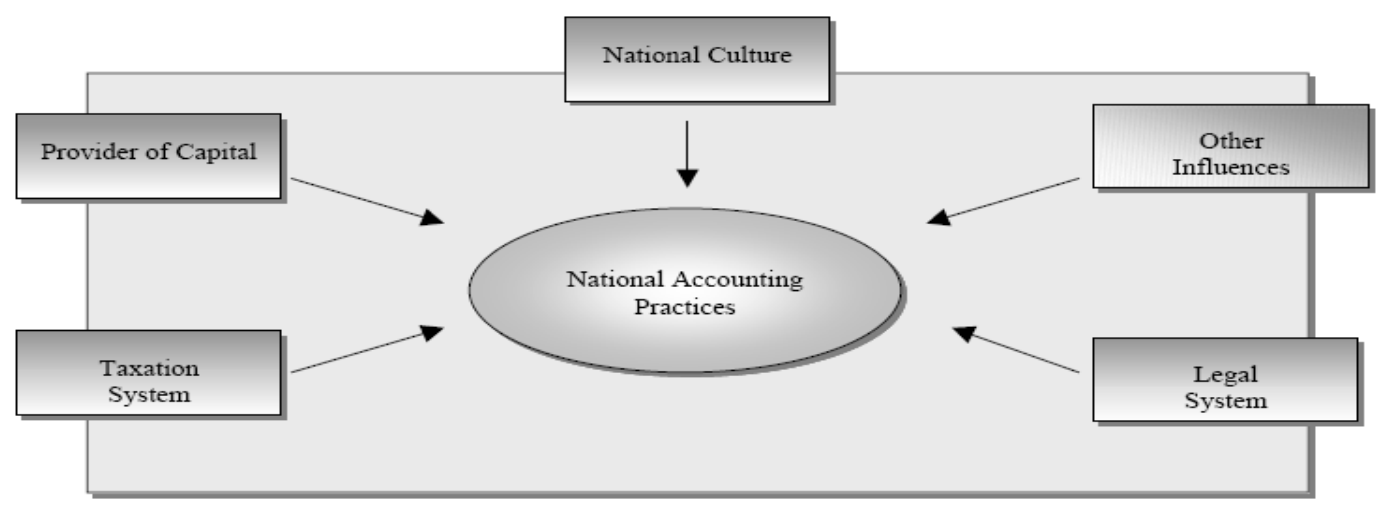

Source: Fritz Susanne and Lammle Christina, (2003) 


\section{Legal System}

There are two types of legal system, the code law and the common law. Nobes et al., (1997:98) claims that there are "those countries which have a 'legalistic' orientation toward accounting and those with a 'no legalistic' orientation". Countries with a non-legalistic orientation toward accounting are those, which use common law. In common law counties, the main purpose of accounting regulations is to protect the owners of the companies. The emphasis is on equity providers (shareholders) rather than creditors or taxation authorities, making measurement rules be less conservative, while the accounting rules are determined by the private sector, from accountant professional organizations and not from the law (Choi et al., 2002).

On the other hand, legalistic approach can be found in the code-law countries where regulations are designed in order to protect creditors. Creditors as well as tax authorities are thought to be the most important users of financial statements and therefore all accountants' rules have often been formulated according to its needs. Shareholders have not generally been seen as so important. In code-law countries the financial statements of individual companies are more highly regulated compared to the group ones, because tax authorities are more interesting in the individual companies for tax reasons. In contrary to the common law, governments have generally regulated accounting rules not the private sector; accounting code is typically prescriptive, detailed and procedural including measurement and bookkeeping rules (Roberts, Weetman and Gordon, 2002).

\section{Taxation System}

In some countries taxation rules and financial reporting regulations are strongly interrelated while in others are totally separated. For example, in common law countries tax and accounting rules are kept separate. Code law countries on the other hand, tend to have common tax and financial reporting regulations.

According to Roberts, Weetman and Gordon, (2002) there are three types of tax systems. The first system refers to these countries where "the tax rules and the financial reporting rules are kept entirely, or very largely, independent of each other". In the second type of tax systems "there is a common system, with many of the financial reporting rules also being used by the tax authorities". In this system tax authorities did not developed detailed rules for the calculation of taxable income. Instead, they are wholly or largely based on reported earnings as the basis of calculating tax liabilities. This gives the incentive to the managers of a company to choose methods, which minimize their tax obligations. The third system involves the countries where "there is a common system, with many of the tax rules also being used for financial reporting purposes"; tax rules are equal to accounting systems (Nobes and Parker, 2000) for calculating the taxable earnings which are these earning including in the financial statements each company preparers (Achleitner, 2000) and tax authorities set detailed rules which have to be followed in the external financial statements. This approach can be found in most countries of Western Europe (Mandilas et al., 2004).

\section{Provider of Finance}

There are three main sources of finance: banks, government and shareholders. The contribution of each of these sources to the creation of the companies' financial capital varies from country to country. For example, banks are the ones, which obtain financial capital to the companies in countries like Germany and France, while shareholders provide capital in countries like England and United States. In countries like France and Sweden the government is the purveyor of capital (Hill, 1999).

This separation of three types of capital sources means that accounting practices differ in order to satisfy the needs of the financial providers. The quality accounting information is of 
a great importance because investors require accurate financial information in order to be able to make good choices when they analyze the financial statements (Gray, McSwenney and Shaw, 1984). This need for more transparent presentation of financial statements can lead a country's accounting setting body to reform its accounting system and adopt IAS (Adhikari and Tondkar, 1992).

On the contrary, this need for quality information is less evident in countries where the main providers of financial capital are banks and government. This is explained by the fact that in these countries, the information will be transferred more directly due to the immediate approach to the economical elements of companies that bank and government have. (Rabebaugh and Gray, 1997).

Therefore, financial statements in countries where shareholders are the main source of capital are "oriented toward providing individual investors with the information they need to make decisions about purchasing or selling corporate stocks and bonds" (Hill, 1999:593). Far from it, countries where most companies are bank-dominated, the accounting practices are focused on the protection of banks' interests. Additionally, the accounting rules in countries, where the main provider of finance is the government, are oriented towards the needs of governmental planners (Hill, 1999).

\section{Culture}

Culture is another factor that influences the regulations of accounting practices. Countries that belong to a specific culture adopt the accounting system prevailed in countries of the same culture (Nobes, 1998).

According to Abd-Elsalam and Weetman, (2003) familiarity and language have a great contribution in the process of adopting new accounting standards. Regarding the adoption of IAS/IFRS, they have proved that both, familiarity and language seem to favor countries in Anglo-American group. This happens firstly because of the prevailing Anglo-American effect in the development of IAS/IFRS and secondly because English is the language that it is used to communicate within the IASB. So the problems Anglo-American countries will face after the adoption of IAS/IFRS will be less and difficulties will easier be solved due to their use of a common language and their cultural vicinity.

Based on Zeghal and Mhedhbi, (2006) there is a positively significant association between the cultural-membership and the adoption of IAS/IFRS.

Roberts et al., (1998) support that dimensions as individualism and uncertainty avoidance are meaningful for accounting and that in a country with highly uncertainty avoidance efforts are made to minimize it. Individualism plays a significant role in accounting in terms of disclosure practises and income measurement. It also orients how willing people are to adopt new rules (Fritz and Lammle, 2003; Nobes and Parker, 2000; Roberts et al., 1998).

Gray, (1998) has also studied culture as an important factor on accounting and proposed how to link culture and accounting by developing four accounting values. Also, classes ten cultural areas: (Asian colonial, Germanic, Less-developed Latin, Less-developed Asian, Near Eastern, Japan, African, More developed Latin, Nordic and Anglo). Subsequently he classes these cultural areas based on their attitudes and on their measurement and disclosure practices.

\section{NOBE'S MODEL}

In his innovative work Nobe's, (1998) examined the reasons which lead to differences in accounting systems. As an accounting system, Nobe's means the accounting practices a company uses in order to prepare its annual financial reporting. An accounting system is not developing as an individual accounting system based on the needs of the predominance capital structure; insider/outsider financiers of the companies depend on the corporate 
governance policy the companies follow. Many countries were prompted to use accounting systems that were followed in other countries because of colonial reasons or because they are rules that used for many years and it is difficult to change them. Also it is a very costly procedure that not many companies or countries can follow.

According to Nobe's, (1998) the insiders are defined as "governments, banks, families and other companies" that "are likely to have close, long-term relationships with their investees", while outsiders "are not members of the board of directors and do not have a privileged relationship with the company". This kind of differentiation between "outsiders" and "insiders" is of the same importance as the rank between "equity" and "creditors". The difference between "equity" and "creditors" refers to the objectives prevailing in accounting systems in order for a company to prepare its annual financial reporting. In a predominant creditors accounting system, the preparers are more interested in calculating reliable and prudent profits, which will give the best results for the distributable and taxable profits. In the mean time in an equity market environment the preparers are trying to provide relevant and reliable information for the performance and the financial condition of a company and thus help the investors make the best decisions.

Based on Nobes's study there are two reporting systems Class A and Class B. Class A refers to strong- equity markets with outsider financiers as the main source of the capital structure of companies in a specific country. Class B occurs when there is a weak-equity market and the main capital sources of a company derive from the insiders' financiers. From the above, it is clear that the accounting system a country or a company might adopt depends on the source of capital finance, which orients the purpose of accounting. Therefore, depending on the purpose of accounting, a company or a country might choose between the accounting classes A or B. The US GAAP, IAS/IFRS, UK GAAP are examples of class A; they are implemented in expanded markets where the companies are important to attract new investors worldwide. These countries are based on the common law where the accounting rules and practices are formed from independent professional setters. Class B represents the code law countries with weak equity market, with more emphasis in the accounting entries and rules, which must be followed from the law. Greek accounting system is alike the French one (La Porta et.al., 1998) which according to Nobe's, (1998) belongs to Class B.

Nobe's tried to classify countries or companies by using 5 propositions. He examined the relationship between cultures, the weak or strong equity markets. His proposed model is depicted in the following figure:

Figure 2: "Nobe's (1998) model for the classification of countries based on two accounting classes"

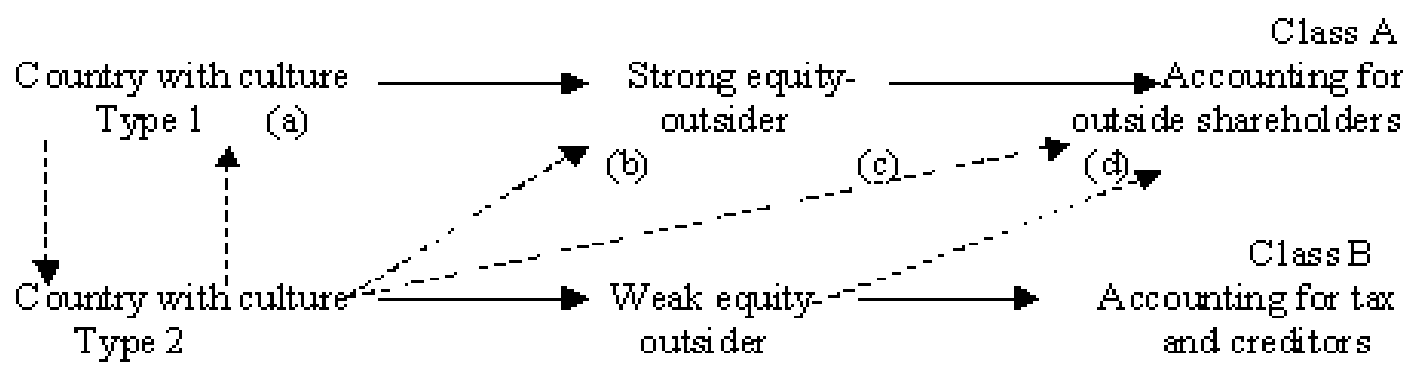

(Source: Nobes, C., 1998)

With his proposed model he claimed that the company's source of finance is the factor that determines the accounting system that is going to be used from a company or a country. 
Weak-equity markets are those with insider financiers and the accounting system they use belongs to Class B. The companies' ranks in this category are financed from insiders who have a straight approach to the companies' information and thus the company does not disclose information, which might interest outsider parts. On the contrary, the Class A accounting system belongs to the strong equity markets with outsider financiers. In this category the company is interested in disclosing relevant information needed from all kind of investors in order to make their decisions and to present a true and fair performance of the firm, giving the incentive to expand its market limits and attract new finance sources. As a result, passage from a Class $\mathrm{B}$ accounting system to Class A means that the company or country needs to adjust its whole financial philosophy to the new reality. It will be based on a more reliable accounting system, which will help the openness of the markets and ensure a more relevant, reliable and accurate disclosure of the information needed in the financial statements. Furthermore, it will enable and the openness to new outsider sources, giving that way the companies the incentive to be more competitive and therefore managing a more healthy economical development for all countries.

\section{CONCLUSION}

The economical expansion to new markets propelled the design of a common international accounting system. In this paper we are trying to figure out and present the factors that are affecting the adoption of International Accounting Standards. These factors are the Legal System, the Taxation system, the Provider of Finance and the culture. Also we are analyzing in depth the Nobe's, (1998) model, which supports, that companies that have more outsider finance are from a weak-equity market and belong to a Class B accounting system (be interested more in creditors and taxes) and are more likely to change to a Class A accounting system (interested more in shareholders and investors, generally in those which have not got an internal relationship with the company).

\section{REFERENCE}

1. Abd-Elsalam, O., \& Weetman, P. (2003), "Introducing International Accounting Standards to an emerging capital market: relative familiarity and language effect in Egypt", Journal of International Accounting, Auditing \& Taxation, Vol.12, No.1.

2. Achleitner, A. (2000), "International - Accounting - Standards: Ein Lehrbuch zur internationalen Rechnungslegung", Franz Vahlen GmbH, Munchen, 2. Auflage.

3. Adhikari, A., \& Tondkar, R.H. (1992), "Environmental factors influencing accounting disclosure Requirements of global stock exchanges", Journal of International Financial Management and Accounting, Vol.4, No.2.

4. Alexander, D., \& Nobes, C. (2004), "Financial Accounting: An International Introduction", Prentice Hall, 2nd Edition.

5. Botosan, C. (1997), "Disclosure Level and the Cost of Capital", The Accounting Review, Vol.72, No. 3.

6. Choi, F. (1973), "Financial Disclosure in Relation to a Firm's Capital Costs”, Accounting and Business Research, Autumn, 1973.

7. Choi, F., Frost, C., and Gary, K. (2002), "International Accounting", Prentice Hall, New Jersey, 4th Edition.

8. Diamond, D.W. \& Verrecchia R.E., (1991), "Disclosure, Liquidity and the Cost of Capital", Journal of Finance, Vol. XLVI, No. 4.

9. Fritz, S., \& Lammle, C. (2003), "The International Harmonization Process of Accounting Standards", Ekonomiska Institutionen Linkoping.

10. Gray, S.J., McSweeney, L.B., Shaw, J.C. (1984), "Information Disclosure and the Multinational Corporation", Wiley Publications. 
11. Gray, S.J. (1998), "Towards a theory of cultural influences on the development of accounting systems internationally", Abacus, Vol.24.

12. Hill, C. (1999), "Competing in the Global Marketplace", Irwin McGraw Hill, Boston, 3rd edition.

13. La Porta, R., Lopez-de-Silanes, F., Shleifer, A. \& Vishny, R.W, (1998), "Law and Finance", Journal of Political Economy, Vol. 106, No. 6.

14. Mandilas, A Athianos,S Tsamis, A Aslani, S, (2004) "The Greek Accounting and Tax Framework. Main Factors of Influence", Accounting and Finance in Transition, Vol 2, ISSN 1743-1999, ISBN 1-86166-204-1.

15. Nobes, C.W. (1998), "Towards a General Model of the Reasons for International Differences in Financial Reporting", Abacus, Vol. 34, No. 2.

16. Nobes, C.W. Mueller, G., Gemon, H., Meek, G. (1997), "Accounting an International Pespective", Richard D. Irwin, Inc; Chicago, 4th edition.

17. Nobes, C.W., \& Parker, R. (2000), "Comparative International Accounting", London: Financial Times/Prentice-Hall, 6th edition.

18. Radebaugh, L.H., \& Gray, S.J. (1997), "International Accounting and Multinational Enterprices", 4th Edition, John Wiley, New York.

19. Roberts, C., Weetman, P., Gordon, P. (1998), "International Financial Accounting - A Comparative Approach", Financial Times Pitman Publishing, London.

20. Zeghal, D., \& Mhedhbi, K. (2006), "An analysis of the factors affecting the adoption of international accounting standards by developing countries", The International Journal of Accounting, Vol.41, No.4. 